\title{
Gert-Joachim Glaeßner \\ Auf der Suche nach einem humanen Sozialismus. Zum Tod von Robert Havemann
}

Wenn die »Frankfurter Allgemeine Zeitung« den Tod des deutschen Kommunisten Robert Havemann in einem längeren Nachruf unter der Überschrift »Er glaubte an das Gute und Humane im Kommunismus« bedenkt, das »Neue Deutschland« dazu aber keine Zeile schreibt, so zeigt sich hierin die ganze Problematik und Widersprüchlichkeit des Lebens eines Mannes, der seit seiner Jugend Kommunist war, der wegen seiner Überzeugungen und seines Widerstandes von den Nazis zum Tode verurteilt wurde, mit vielen Antifaschisten, unter ihnen Erich Honecker, im Zuchthaus Brandenburg eingekerkert war und überlebte, der in seinem Leben dreimal vom Berufsverbot betroffen war - 1933 als ihn die Nationalsozialisten aus dem Kaiser-Wilhelm-Institut für Physikalische Chemie entließen, 1950 als ihn die Amerikaner wegen seines Engagements gegen den Bau der Wasserstoffbombe als Abteilungsleiter des gleichen Instituts absetzten und 1964 als er seine Professur an der Humboldt-Universität in (Ost)Berlin verlor, weil er in einer Vorlesungsreihe zentrale Axiome des poststalinistischen Marxismus-Leninismus in Frage gestellt hatte.

Seitdem galt er den einen als »Dissident«, als Kronzeuge gegen den staatlich etablierten Sozialismus sowjetischen Typs, den anderen als Verräter an der großen Sache der Befreiung der Menschheit durch die marxistisch-leninistische Avantgardepartei. Havemann war kein Dissident, er war nicht aus der »Glaubensgemeinschaft« der Marxisten-Leninisten ausgetreten, sie hat sich vielmehr eines Kritikers entledigt, der sie von innen kritisierte, er war schon gar nicht ein Konvertit, der vom »wahren Glauben« abgewichen ist und die weltanschaulichen Fronten gewechselt hat wie viele vor ihm, noch war er ein Häretiker, der sich einer »Irrlehre" verschrieben hatte. Er bestand vielmehr darauf, daß der Marxismus mehr sei als eine neue Theologie, mehr als eine pure Rechtfertigungsideologie der herrschenden Partei, mehr als ein Instrument zur Disziplinierung der vorgeblichen Subjekte der Geschichte, der arbeitenden Massen und mehr als der platte Pragmatismus der NÖS-Generation in der DDR. Er wandte sich gegen einen mechanischen Materialismus, der keinen Raum läßt für aktives, selbstverantwortliches Handeln. Demgegenüber betonte er die Notwendigkeit einer neuen Moral, nahm die ethischen Imperative des frühen Marxismus wieder auf:

"Die Grundelemente der alten Moral waren: Demut, Ergebenheit in das Schicksal, Hoffnung auf eine höhere Gerechtigkeit. Einordnung des Menschen in die gesellschaftliche Hierarchie. In der sozialistischen Moral sind andere Begriffe wesentlich: Die Solidarität, der Widerstand, der Zweifel an allem Hergekommenen, das Selbstvertrauen, die Entschlossenheit, die Verhältnisse zu ändern.«.

\section{Havemann und die DDR}

Havemann hat immer darauf bestanden, daß die DDR »auf dem Weg in die Zukunft, die Sozialismus heißt, der westdeutschen Bundesrepublik und den anderen westeuropäischen Industriestaaten weit voraus«sei. Er hoffte, daß die DDR gemeinsam mit den anderen so- 
fung der Repression in den Ländern des »realen Sozialismus« zu interpretieren, kann sich nicht auf Robert Havemann berufen, der die Bedeutung der friedlichen Koexistenz immer wieder betont hat und dessen Engagement in der Friedensbewegung ganz wesentlich aus der Furcht vor den Folgen eines neuen kalten Krieges erwuchs.

Ein pauschalisierendes Freund-Feind-Denken, das die DDR nur als Negativfolie für die innenpolitische und innerlinke Auseinandersetzung benutzt, kann Havemanns Positionen nicht für sich vereinnahmen: Von hier bis zu einem neuen (»linken«) Antikommunismus ist nur ein kleiner Schritt. Havemann hat immer wieder den Antikommunismus als schlimme Krankheit bezeichnet, »die in vielen Ländern die Kraft der Arbeiterbewegung lähmt und die Spaltung der Progressiven aller Schattierungen fördert. ${ }^{5}$ Er dient dazu, das äußere und innere Feindbild zu schärfen. Wie schmal der Grat zwischen der scharfen Kritik an den Deformationen des »realen Sozialismus« und der Vereinnahmung dieser Kritik für antikommunistische Positionen ist, hat bisher noch jeder linke Kritiker dieser Länder erfahren. Havemann war nicht zu vereinnahmen, weil er trotz alledem die DDR als historische Möglichkeit und Chance begriff, aus den bisherigen Fehlern zu lernen, und weil seine Kritik fundiert war, auf einer subtilen Kenntnis und Binnenerfahrung des Systems und seiner Apparate beruhte.

Die Schwierigkeiten der Linken mit Robert Havemann liegen vor allem darin, daß sie über diese Erfahrungen nicht verfügt und verfügen kann, deswegen aber auch Schwierigkeiten hat, die Widersprüche und Brüche zu verstehen, die im Denken und Handeln eines deutschen Kommunisten entstanden sind, der von seinem Traum eines humanen Sozialismus in der DDR nicht lassen wollte, obwohl alle Erfahrung ihn hätte davon lehren müssen, daß dieser Traum am 21. August 1968 in Prag zerstört wurde.

\section{Anmerkungen}

1 Robert Havemann: Dialektik ohne Dogma? Naturwissenschaft und Weltanschauung, Reinbek 1964, S. 151.

2 Robert Havemann: Zehn Thesen zum 30. Jahrestag der Deutschen Demokratischen Republik, in: Frankfurter Rundschau vom 3.10.1979, S. 17.

3 Dialektik, S. 159

4 Dialektik, S. 153

5 Robert Havemann: Berliner Schriften, München 1977, S. 39. 